\title{
Cost-effectiveness of adding vaccination with the AS04-adjuvanted human papillomavirus 16/18 vaccine to cervical cancer screening in Hungary
}

\author{
Zoltán Vokó ${ }^{1,2,3^{*}}$, László Nagyjánosi ${ }^{2}$ and Zoltán Kaló1,2
}

\begin{abstract}
Background: The cervical cancer screening program implemented in Hungary to date has not been successful. Along with screening, vaccination is an effective intervention to prevent cervical cancer. The aim of this study was to assess the cost-effectiveness of adding vaccination with the human papillomavirus 16/18 vaccine to the current cervical cancer screening program in Hungary.

Methods: We developed a cohort simulation state-transition Markov model to model the life course of 12-year-old girls. Eighty percent participation in the HPV vaccination program at 12 years of age was assumed. Transitional probabilities were estimated using data from the literature. Local data were used regarding screening participation rates, and the costs were estimated in US \$. We applied the purchasing power parity exchange rate of $129 \mathrm{HUF} / \$$ to the cost data. Only direct health care costs were considered. We used a 3.7\% discount rate for both the cost and quality-adjusted life years (QALYS). The time horizon was 88 years.

Results: Inclusion of HPV vaccination at age 12 in the cervical cancer prevention program was predicted to be cost-effective. The incremental cost-effectiveness ratio (ICER) of adding HPV vaccination to the current national cancer screening program was estimated to be 27588 \$QALY. The results were sensitive to the price of the vaccine, the discount rate, the screening participation rate and whether herd immunity was taken into account.

Conclusions: Our modeling analysis showed that the vaccination of 12-year-old adolescent girls against cervical cancer with the AS04-adjuvanted human papillomavirus 16/18 vaccine would be a cost-effective strategy to prevent cervical cancer in Hungary.
\end{abstract}

Keywords: Cervical cancer, Human papillomavirus, Vaccine, Cervarix, Hungary, Cost-effectiveness

\section{Background}

Since the introduction of human papillomavirus (HPV) vaccines, both primary and secondary preventive (i.e., screening) measures have been available to prevent cervical cancer. Health policy makers need to answer the following question: what is the most effective and cost-effective strategy for cervical cancer prevention in a certain country?

Although there is insufficient evidence regarding the effectiveness of cervical screening (Pap-smear) among vaccinated women [1], most policy recommendations

\footnotetext{
* Correspondence: vokoz@t-online.hu

'Department of Health Policy \& Health Economics, Institute of Economics, Faculty of Social Sciences, Eötvös Loránd University, 1117 Budapest, Pázmány Péter sétány $1 / a$, Hungary

${ }^{2}$ Syreon Research Institute, 1146 Budapest, Thököly út, 119, Hungary Full list of author information is available at the end of the article
}

advocate continuation of the screening programs in vaccinated women because current vaccines do not provide protection against all oncogenic types of HPV and because the overall vaccine efficacy against cervical cancer is less than $100 \%$ [2-4].

Thus, the relevant question from the health policy perspective is whether introducing a cervical cancer vaccination program for adolescents in parallel with the screening program is cost-effective.

The organized cervical screening program was launched for women aged 25-65 in 2003 as part of the National Public Health Program in Hungary aiming to target those women who otherwise would not use the service. Unfortunately, the organized screening program had only a small positive effect on the percentage of the

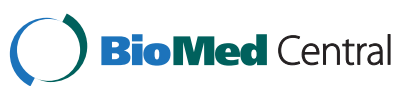

$$
\text { (a) }
$$

(c) 2012 Vokó et al.; licensee BioMed Central Ltd. This is an Open Access article distributed under the terms of the Creative Commons Attribution License (http://creativecommons.org/licenses/by/2.0), which permits unrestricted use, distribution, and reproduction in any medium, provided the original work is properly cited. 
population that participated in regular screening $[5,6]$. Improving the effectiveness of the cervical cancer prevention program is on the agenda of Hungarian health policy makers. We have recently developed a health economic model to study the cost-effectiveness of different possible screening strategies [7].

In addition to the development of the current screening program, policy makers need to decide whether to introduce vaccination against cervical cancer. The vaccination of adolescent girls is the most likely form of vaccination to be added to the program. There are two vaccines available for preventing cervical cancer. One of these is Cervarix ${ }^{\mathrm{TM}}$, an AS04-adjuvanted bivalent vaccine against HPV types 16 and 18 produced by GlaxoSmithKline. The second vaccine, Gardasil ${ }^{\mathrm{TM}}$, is active against HPV types $6,11,16$ and 18 . The purpose of this study was to assess the cost-effectiveness of adding vaccination with the AS04-adjuvanted human papillomavirus 16/18 vaccine (Cervarix ${ }^{\mathrm{TM}}$ ) at age 12 to the current national cervical screening program. We have not considered screening methods other then the prevailing one in the national cervical cancer screening program.

\section{Methods}

We developed a cohort simulation state-transition Markov-model using Microsoft Excel software. The model estimates the life course of 12-year-old girls.

The disease progression part of the cost-effectiveness model was based on a previously published model (Figure 1) [7-9]. The boxes represent health states, and the arrows represent transition routes between the health states. We calculated the transition probabilities for a cycle length of one month assuming a constant incidence rate for one cycle (see these incidences in Additional file 1). The time horizon of the model was 88 years, i.e., the accumulated costs and QALY differences were estimated at age 99 years.
Data on quality-of-life (QoL) weights were taken from a previously published Hungarian model assessing the costeffectiveness of different screening strategies (Table 1) [7].

The discount rates of cost and quality of life years (QALY) are user inputs in the model. For the base case, we used $3.7 \%$ for both discount rates, which is in line with the recommendation of the working group on discount rates in health economic analysis lead by the $\mathrm{Na}$ tional Health Fund. We also provide the results calculated with a discount rate of $5 \%$, which is specified in the current Hungarian guidelines for health economic evaluations [10]. Our analysis was conducted from the public health care payer's perspective.

\section{Screening}

An organized cervical cancer screening program was launched for women aged 25 to 65 years in 2003 as part of the National Public Health Program. Women were invited to undergo cervical screening every 3 years. The method of screening followed the longstanding Hungarian professional tradition of opportunistic screening; it included Papanicolaou test and colposcopic examination performed by gynecologists in outpatient services located in cities. Regarding the procedures following the screening test, if a person has a Papanicolaou 3 (P3) cytology result, she receives a combination of local antiinflammatory treatment and the cytology is repeated within 2 weeks. If the subsequent result is P3 or worse again, then conization is offered just like for those who had a P4 or P5 result initially. If the subsequent result after an initial P3 cytology is P2, then the cytology is repeated again in 6 months. If this result is Papanicolaou 1 (P1) or Papanicolaou 2 (P2), then the patient returns to the regular screening regimen. If the result is worse than P2, conization is offered.

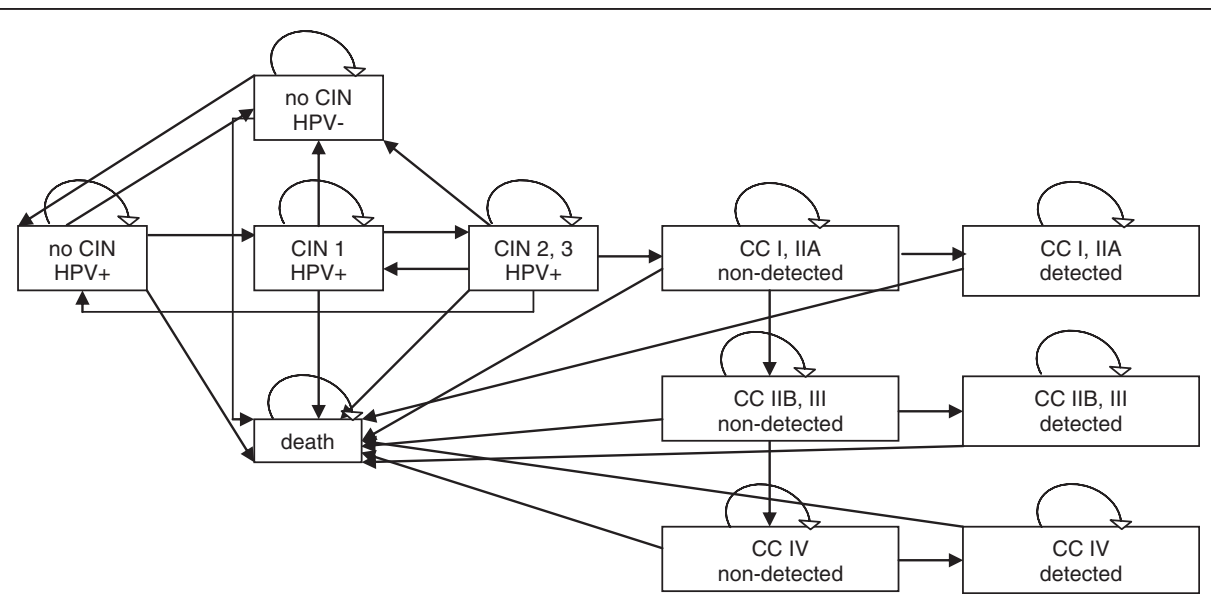

Figure 1 Health states used in the disease progression model. CIN: cervical intraepithelial neoplasia, CC: cancer, HPV: human papilloma virus. 
Table 1 Quality of life weights* corresponding to different cancer stages

\begin{tabular}{lccc}
\hline & Non-detected & Newly detected & Treated \\
\hline CC I-IIA & $1.0(0.1000)$ & $0.68(0.0680)$ & $0.95(0.0950)$ \\
\hline CC IIB-III & $0.95(0.0950)$ & $0.56(0.0560)$ & $0.75(0.0750)$ \\
\hline CC IV & $0.9(0.0900)$ & $0.48(0.0480)$ & $0.60(0.0600)$
\end{tabular}

The numbers in brackets are the standard errors applied for the distributions in the probabilistic sensitivity analysis.

*The age specific quality of life weights are multiplied with these weights.

In line with the current practice, screening was assumed to occur every 3 years in the model. The proportion of women starting and stopping cervical screening can be set in the model at each screening period, allowing great flexibility of modeling different uptakes of screening at different ages. In the default setting, we set the proportion of women starting and stopping screening at each round of the screening in such a way that the participation rates were in line with the current agespecific participation rate figures (Table 2) [11]. The data on the test characteristics of the combined test of cytologic and colposcopic examinations were taken from our model for cervical screening (Table 3) [7].

\section{Vaccination}

Three different vaccination strategies can be modeled: no vaccination, vaccination at age 12 with lifetime protection assumed, and vaccination at age 12 plus booster

Table 2 Proportion of the population screened within three years by age group

\begin{tabular}{|c|c|}
\hline Age group (years) & Percentage screened \\
\hline $12-17$ & $0 \%$ \\
\hline 18 & $32 \%$ \\
\hline 21 & $52 \%$ \\
\hline 24 & $62 \%$ \\
\hline 27 & $65 \%$ \\
\hline 30 & $66 \%$ \\
\hline 33 & $66 \%$ \\
\hline 36 & $63 \%$ \\
\hline 39 & $61 \%$ \\
\hline 42 & $56 \%$ \\
\hline 45 & $53 \%$ \\
\hline 48 & $51 \%$ \\
\hline 51 & $50 \%$ \\
\hline 54 & $49 \%$ \\
\hline 57 & $40 \%$ \\
\hline 60 & $36 \%$ \\
\hline 63 & $32 \%$ \\
\hline 66 & $27 \%$ \\
\hline 69 & $22 \%$ \\
\hline$>69$ & $0 \%$ \\
\hline
\end{tabular}

Table 3 The default setting of the distribution of the screening test results according to the disease stages

\begin{tabular}{lccccc}
\hline & \multicolumn{5}{c}{ Stage } \\
\cline { 2 - 6 } Test result & Normal & CIN 1 & CIN 2,3 & CC I & CC II-IV \\
\hline P1-2 & 0.31 & 0.1 & 0.04 & 0.01 & 0 \\
\hline P3 & 0.621 & 0.45 & 0.48 & 0.04 & 0 \\
\hline P4-5 & 0.069 & 0.45 & 0.48 & 0.95 & 1 \\
\hline
\end{tabular}

CIN: cervical intraepithelial neoplasia, CC: cancer, P: Papanicolaou.

vaccination 20 years later assuming a waning of the vaccine efficacy after 20 years.

The efficacy of vaccination was modeled as the product of the proportion of cervical cancers caused by the oncogenic HPV types that the vaccine provides protection against and the vaccine efficacy against a 6-month persistent infection with these types of HPV. For the former, $71.5 \%$ was used as the default value because that is the proportion of cervical cancers that can be attributed to HPV types 16 and 18 in Europe [12]. The vaccine efficacy against persistent HPV 16/18 infection was modeled as $94.3 \%$ [13]. We took into account crossprotection against other types of HPV in the sensitivity analysis of the model because the vaccine provides significant protection not only for HPV types 16 and 18 but also for HPV types 33, 31 and 45 (Table 4) [14]. Although the model did not directly distinguish the different high risk HPV types, this way we could model the efficacy considering different HPV types. Additionally, we performed sensitivity analysis with the intention-totreat estimate of the efficacy parameter, which was $90.2 \%$ in all vaccinated subjects who had received at least one dose, for whom data concerning efficacy endpoint measures were available and who had a normal or low-grade cytology (defined as negative, or ASCUS or LSIL) at month 0 [13]. The incidence among vaccinated persons was assumed to be decreased by the vaccine efficacy.

Current evidence suggests long-term vaccine efficacy $[14,15]$. Mathematical modeling predicts that the AS04adjuvanted HPV 16/18 vaccine provides long-lasting

Table 4 Cervical cancers attributable to different types of HPV and protection against 6-month persistent infections by the AS04-adjuvanted bivalent vaccine

\begin{tabular}{|c|c|c|c|c|}
\hline \multirow[t]{2}{*}{ HPV type } & \multirow[t]{2}{*}{$\begin{array}{l}\text { Cervical cancers } \\
\text { attributable to } \\
\text { the type (\%) }\end{array}$} & \multirow[t]{2}{*}{$\begin{array}{l}\text { Vaccine } \\
\text { efficacy } \\
(\%)\end{array}$} & \multicolumn{2}{|c|}{$\begin{array}{l}\text { Vaccine efficacy } \\
\text { against oncogenic } \\
\text { infection (\%) }\end{array}$} \\
\hline & & & $\begin{array}{l}\text { Without cross- } \\
\text { protection }\end{array}$ & $\begin{array}{l}\text { With cross- } \\
\text { protection }\end{array}$ \\
\hline 16 & 65.4 & 94.3 & 67.42 & 75.33 \\
\hline 18 & 6.1 & & & \\
\hline 33 & 5.6 & 45.1 & & \\
\hline 31 & 4.1 & 77.5 & & \\
\hline 45 & 2.9 & 76.1 & & \\
\hline
\end{tabular}


high antibody levels against HPV types 16 and 18 $[16,17]$. Based on the current evidence, we did not assume waning immunity in the base; nevertheless, in the sensitivity analysis, we assessed the cost-effectiveness assuming that the vaccine efficacy decreases to $50 \%$ from 20 to 30 years after vaccination and a booster is given 20 years after the first immunization in $80 \%$ of women vaccinated at the age of 12 .

Vaccination coverage can be set for both the initial vaccination and for the booster dose as a percentage of the cohort; the base case values were $80 \%$ for the former and $0 \%$ for the latter. Vaccination coverage had relevance if herd immunity was taken into account. Herd immunity was modeled by applying an additional reduction in the incidence rate from state "No CIN, HPV negative" to the state "No CIN, HPV positive". The incidence rate applied was inversely related to the vaccination coverage rate and the vaccine efficacy. The incidence rate in the population was estimated as the weighted average of the expected incidence among nonvaccinated and vaccinated persons, where the weights were the proportions of these subpopulations. Herd immunity was taken into account in the base case scenario. If the vaccination coverage did not reach $30 \%$, the model did not take into account the herd immunity effect.

For the base case, no decrease in the quality of life due to the vaccination was assumed.

\section{Cost data}

The cost of the screening process and cancer treatment was taken from a previously published model (Table 5) [7]. The nominal prices paid by the National Sick Fund for the units of in- and outpatient services have increased by $2.74 \%$ since the cost estimation was performed for the previous model. Therefore, we updated the cost data accordingly. The initial model included costs in Hungarian forints. These costs were converted to US\$ based on the purchasing power parity exchange rate of $129 \mathrm{HUF} / \$$ (2010) to eliminate differences in price levels between countries [18]. Resource utilization data of the screening process was estimated per protocol: resource units were multiplied by the tariffs of the

Table 5 Direct medical cost (\$) per month of cervical cancer by stages and time after the diagnosis

\begin{tabular}{llccc}
\hline \multirow{2}{*}{ Stage } & \multicolumn{4}{c}{ Time after the diagnosis } \\
\cline { 2 - 5 } & Months 0-3 & Months 4-12 & Months 13-24 & $\begin{array}{c}\text { From } \\
\text { month 25 }\end{array}$ \\
\hline CC I-IIa & $1157(289.20)$ & $216(54.05)$ & $158(39.39)$ & $99(24.72)$ \\
\hline CC IIb-III & $11157(289.20)$ & $353(88.51)$ & $339(84.54)$ & $283(70.56)$ \\
\hline CC IV & $11157(289.20)$ & $352(87.90)$ & $447(111.82)$ & $328(81.98)$ \\
\hline
\end{tabular}

The numbers in brackets are the standard errors applied for the distributions in the probabilistic sensitivity analysis.

CC: cancer.
National Health Insurance Fund for the services. The costs of the Pap-smear (National Health Insurance Fund (NHIF) procedure code: 14720), the cytological examination (NHIF procedure code: 42700) and of the gynecological screening examination (NHIF procedure code 16631 plus 42600 ) were $\$ 0.73, \$ 12.7$ and $\$ 12,12$, respectively. The price of local anti-inflammatory treatment was $\$ 6.24$. The cost of the conisation was $\$ 1,495.2$. The cost of conisation was calculated by the cost of the diagnosis-related group "operation of uterus and adnexum of uterus due to in situ carcinoma and nonmalignant disease" coded as 643B.

We used the European Economic Area's lowest official public price of the vaccine, $\$ 131.08$, in the analysis because if the vaccination is included in the national vaccination scheme in Hungary as a $100 \%$ reimbursed vaccine, then its price cannot be higher than that because of reference pricing rules. Three doses of the vaccine are required for the basic immunization.

We did not consider indirect costs in the analysis.

\section{Sensitivity analysis}

We tested the robustness of the results to $10 \%$ increases and decreases in the input parameters. In the probabilistic sensitivity analysis, we defined distributions for the key input parameters and ran 5000 Monte-Carlo simulations with sampling from these distributions. Gamma distributions were applied to the incidence rates of transitions, the participation rates, the cancer stage-specific mortality, the stage-specific health care costs and the organizational costs of screening. Ten percent of the point estimates was used as standard error of the parameters. Beta distributions were applied to the screening participation rates and the quality-of-life weights of the cancer states. Twenty-five percent of the point estimates was used as standard error of the parameters. Dirichlet distribution was used for the sensitivity and specificity of the screening test. We did not use standard errors for the parameters with Dirichlet distribution. We plotted the results on an incremental cost-effectiveness ratio scatter plot and on an acceptability curve to determine the proportion of the simulated results that were below the cost-effectiveness threshold.

\section{Results}

Table 6 shows the costs and the QALYs corresponding to the vaccination and no-vaccination strategies. The incremental cost-effectiveness ratio of vaccination was 27 588 \$/QALY. Table 7 shows that the cost-effectiveness of vaccination was very sensitive to some of the key input parameters, including the price of the vaccine, the discount rate and whether herd immunity was taken into account. Without herd immunity, the ICER changed from 27588 to 42520 \$/QALY. With the use of the 
Table 6 Estimated cost-effectiveness of the different strategies

\begin{tabular}{llcc}
\hline Strategy & QALY & Cost $\mathbf{( \$ )}$ & ICER (\$/QALY) \\
\hline no vaccination & 22.427 & 3348.8 & reference \\
\hline vaccination & 22.437 & 3629.2 & 27588 \\
\hline
\end{tabular}

QALY: quality-adjusted life years, ICER: incremental cost-effectiveness ratio.

intention-to-treat vaccine efficacy parameter, the ICER slightly increased to 28662 \$/QALY. When crossprotection was taken into account, the ICER decreased to 25190 \$/QALY. Assuming that the vaccine efficacy waned after 20 years, requiring the administration of a booster dose, largely decreases the cost-effectiveness.

The results of the detailed deterministic and the probabilistic sensitivity analyses are presented in the online Additional file 2.

\section{Discussion}

Our study aimed to provide health economic data to inform the development of the Hungarian cervical cancer prevention program. First, the national program needs to address the problem of the inefficiency of the current screening program $[5,6]$. We have previously developed a health economic model to support this decision making process [7]. Furthermore, with the introduction of vaccination against cervical cancer, a new policy question was raised: whether to include the vaccination of adolescent girls in the cervical cancer prevention program. We aimed to analyze this question from a health economic perspective.

Our modeling results predicted that adding vaccination of adolescent girls with the AS04-adjuvanted human papillomavirus $16 / 18$ vaccine to the national cervical cancer screening program would be cost-effective in Hungary. Although our results were quite robust to

Table 7 The effect of major input parameters on the estimated cost-effectiveness of adding vaccination to screening

\begin{tabular}{|c|c|c|c|}
\hline & $\triangle Q A L Y$ & $\Delta \operatorname{cost}(\$)$ & ICER (\$/QALY) \\
\hline base case & 0.01016 & 280.396 & 27588 \\
\hline no herd immunity & 0.00857 & 364.382 & 42520 \\
\hline $\begin{array}{l}\text { with intention-to-treat } \\
\text { efficacy parameter }\end{array}$ & 0.00982 & 281.534 & 28662 \\
\hline with cross-protection & 0.01102 & 277.560 & 25190 \\
\hline $\begin{array}{l}50 \% \text { waning of efficacy } \\
\text { from } 20 \text { to } 30 \text { years after } \\
\text { vaccination and booster } \\
\text { dose in } 80 \% \text { of persons } \\
\text { immunized at age } 12 \text { years } \\
\text { and alive after } 20 \text { years }\end{array}$ & 0.00728 & 332.731 & 45709 \\
\hline discount rate $5 \%$ & 0.00532 & 295.598 & 55617 \\
\hline price of the vaccine $231 \$^{*}$ & 0.01016 & 520.210 & 51184 \\
\hline
\end{tabular}

* current recommended market price of the Cervarix vaccine in Hungary. QALY: quality-adjusted life years, ICER: incremental cost-effectiveness ratio. the uncertainty in the input parameters, larger changes in the most influential parameters could considerably change the result.

An important question from the policy perspective is whether a catch-up vaccination for older girls/women would be beneficial and cost-effective. Studying this question was outside the scope of our analysis because catch-up vaccination against cervical cancer is not under consideration in the Hungarian health policy agenda.

Our analysis can be considered a conservative one because we did not consider potential health benefits of vaccination other than preventing cervical cancer, including protection against other diseases. This lack of consideration of other potential benefits is true for the screening test as well. Some gynecological abnormalities can be detected when the cervical smear is taken. Furthermore, we did not include indirect costs in our analysis. Another limitation of our study is that the reported cost-effectiveness can be expected only after a few years time because it is necessary for the incidence of HPV among the partners of an actually vaccinated population to decrease for herd immunity to develop. Furthermore, we did not use a dynamic transmission model, and did not model the incidence of the different HPY types. Therefore, our method of modeling the effect of the herd immunity can be considered a simple tool to project the main features of the potential impact of HPV vaccines at the population level. Additionally, our model was somewhat undercalibrated in the young age groups, and it was well calibrated only above age 44 years, i.e. the number of the estimated new cases with the current screening practice and no vaccination was consistent with the actual incident cases registered in the National Cancer Registry above age 44 years [7].

Many modeling studies have been published that investigated the cost-utility of adding HPV vaccination to existing screening programs in different countries [19-36]. The direct comparison of the results is not possible, because of the differences in the methods and because of the differences in the input parameters. The studies themselves and their reviews highlighted the limitations of the transferability of health economic evaluations [37-42]. Most of the variations can be explained by the differences in the model structures (e.g., modeling herd immunity or not) and in the influential input parameters (e.g., the incidence of cervical cancer related to the effectiveness of the screening, the cost of the vaccine, waning of the vaccine efficacy, the use of booster vaccination, and the value of the discount rate). The huge effect of the discount rate on these published results and on our results highlights the challenges involved in the health economic analysis of primary preventive programs. In these programs, the return of an early investment can be expected in the long run in the 
form of improved health; thus, the discount hardly affects the cost, but it devalues the benefit.

A cost-effectiveness analysis of the quadrivalent (6/11/ 16/18) HPV vaccine in Hungary has already been published [43]. The authors reported that the incremental cost-effectiveness ratio of adding vaccination at age 12 years to the current screening program was 9577 $€ /$ QALY, which is equivalent to $\$ 18901$ when using the $€ /$ HUF exchange rate given the authors used and the purchasing power parity exchange rate of $129 \mathrm{HUF} / \$$. In addition to the differences between the vaccines studied, the major methodological differences between studies make it difficult to compare our results with those of that analysis. First, our model tracks a cohort, whereas the other model follows a population of fixed size at any time point. Hence, the compositions of the numerators and denominators used in the ICERs differ between the models. Second, the results of the other study accounted for the additional benefits conferred by protecting against HPV 6/11 infection. Finally, the states that were modeled and the parameters applied differed as well.

\section{Conclusions}

Our model predicted that adding vaccination of 12-yearold adolescent girls with the AS04-adjuvanted human papillomavirus $16 / 18$ vaccination to the national cervical screening program would be a cost-effective strategy to prevent cervical cancer in Hungary.

\section{Additional files}

Additional file 1: Age specific incidence rates of the transitions from one state to another. MS-Excel format. HPV: human papilloma virus, CC: cancer, CIN: cervical intraepithelial neoplasia.

Additional file 2: Results of the deterministic and probabilistic sensitivity analyses. Figure 1: Sensitivity of the cost-effectiveness to $10 \%$ increases and decreases in the most influential input parameters. Figure 2: Cost-effectiveness acceptability curve.

\section{Abbreviations}

HPV: Human papillomavirus; QALY: Quality-adjusted life years; QoL: Quality-of-life.

\section{Competing interests}

This work was financially supported by GlaxoSmithKline Hungary, Ltd. GlaxoSmithKline manufactures Cervarix ${ }^{\mathrm{TM}}$

\section{Authors' contributions}

All of the authors participated in the design of the study. ZV developed the structure of the model. LN and ZV collected the data on the input parameters. LN performed the programming. ZK supervised the work and tested and further developed the model. ZV drafted the first version of the manuscript. All authors participated in the revision of the manuscript and approved the final version.

\section{Acknowledgments}

We greatly appreciate the financial support of GlaxoSmithKline (GSK) Hungary, Ltd provided for Syreon Research Institute to perform this work. GSK was involved in the writing of the manuscript, approved its publication, and paid the article-processing fee.

\section{Author details}

${ }^{1}$ Department of Health Policy \& Health Economics, Institute of Economics, Faculty of Social Sciences, Eötvös Loránd University, 1117 Budapest, Pázmány Péter sétány 1/a, Hungary. ${ }^{2}$ Syreon Research Institute, 1146 Budapest, Thököly út, 119, Hungary. ${ }^{3}$ National Institute for Health Development, 1094 Budapest, Nagyvárad tér 2, Hungary.

Received: 29 December 2011 Accepted: 18 October 2012 Published: 30 October 2012

\section{References}

1. US Preventive Services Task Force: Recommendations on screening for cervical cancer. http://www.uspreventiveservicestaskforce.org/uspstf11/ cervcancer/cervcancerrs.htm.

2. Saslow D, Castle PE, Cox JT, Davey DD, Einstein MH, Ferris DG, Goldie SJ, Harper DM, Kinney W, Moscicki AB, Noller KL, Wheeler CM, Ades T, Andrews KS, Doroshenk MK, Kahn KG, Schmidt C, Shafey O, Smith RA: Partridge EE; Gynecologic Cancer Advisory Group, Garcia F: American Cancer Society Guideline for human papillomavirus (HPV) vaccine use to prevent cervical cancer and its precursors. CA Cancer J Clin 2007, 57:7-28.

3. American College of Obstetricians and Gynecologists (ACOG): Cervical cytology screening. ACOG Practice Bull 2009, 109.

4. World Health Organization: Cervical cancer, human papillomavirus (HPV), and HPV vaccines - Key points for policy-makers and health professionals. Geneva: WHO; 2010.

5. Boncz I, Sebestyén A, Ember I: Organized, nationwide cervical screening programme in Hungary. Gynecol Oncol 2007, 106:272-273.

6. Kovács A, Döbrössy L, Budai A, Boncz I, Cornides A: Cervical screening in Hungary: why does the "English model" work but the "Hungarian model" does not? Eur J Gynaecol Oncol 2008, 29:5-9.

7. Vokó Z, Nagyjánosi L, Margitai B, Kövi R, Tóth Z, László D, Kaló Z: Modeling cost-effectiveness of different scenarios of cervical screening in Hungary. Value Health 2012, 15:39-45.

8. Goldhaber-Fiebert JD, Stout NK, Ortendahl J, Kuntz KM, Goldie SJ, Salomon JA: Modeling human papillomavirus and cervical cancer in the United States for analyses of screening and vaccination. Popul Health Metr 2007, 5:11.

9. Goldhaber-Fiebert JD, Stout NK, Ortendahl J, Kuntz KM, Goldie SJ, Salomon JA: An individual-based stochastic microsimulation of human papillomavirus and cervical cancer in the United States. Model structure, parameterization, calibration, evaluation, screening and vaccination strategies: Supplemental technical information; 2009. Available from: http://www.pophealthmetrics. com/content/5/1/11/additional/. [Accessed March 3, 2009].

10. Szende A, Mogyorósy Z, Muszbek N, Nagy J, Pallos G, Dózsa C Methodological guidelines for conducting economic evaluation of healthcare interventions in Hungary: a Hungarian proposal for methodology standards. Eur J Health Econ 2002, 3:196-206.

11. Boncz I, Sebestyén A, Döbrössy L, Kovács A, Budai A, Székely T: A méhnyakszűrés részvételi mutatói Magyarországon (in Hungarian) [The coverage of cervical screening in Hungary]. Orv Hetil 2007, 148(46):2177-82

12. Munoz N, Bosch FX, Castellsagué X, Díaz M, de Sanjose S, Hammouda D, Shah KV, Meijer CJ: Against which human papillomavirus types shall we vaccinate and screen? The international perspective. Int J Cancer 2004, 11:278-285

13. European Medicine Agency: CHMP variation assessment report Type II variation EMEA/H/C/000721//1/0011. 2010 http://www.ema.europa.eu/docs/ en_GB/document_library/EPAR_-_Assessment_Report_-_Variation/human/ 000721/WC500098066.pdf.

14. Ault KA: Long-term efficacy of human papillomavirus vaccination. Gynecol Oncol 2007, 107(2 Suppl 1):27-30.

15. GlaxoSmithKline Vaccine HPV-007 Study Group, Romanowski B, de Borba PC, Naud PS, Roteli-Martins CM, De Carvalho NS, Teixeira JC, Aoki F, Ramjattan B, Shier RM, Somani R, Barbier S, Blatter MM, Chambers C, Ferris D, Gall SA, Guerra FA, Harper DM, Hedrick JA, Henry DC, Korn AP, Kroll R, Moscicki AB, Rosenfeld WD, Sullivan BJ, Thoming CS, Tyring SK, Wheeler CM, Dubin G, Schuind A, Zahaf T, Greenacre M, Sgriobhadair A: Sustained efficacy and immunogenicity of the human papillomavirus (HPV)-16/18 AS04-adjuvanted vaccine: analysis of a randomised placebo-controlled trial up to 6.4 years. Lancet 2009, 374:1975-1985. 
16. Fraser C, Tomassini JE, Xi L, Golm G, Watson M, Giuliano AR, Barr E, Ault KA Modeling the long-term antibody response of a human papillomavirus (HPV) virus-like particle (VLP) type 16 prophylactic vaccine. Vaccine 2007 25:4324-4333.

17. David MP, Van Herck K, Hardt K, Tibaldi F, Dubin G, Descamps D, Van Damme P: Long-term persistence of anti-HPV-16 and -18 antibodies induced by vaccination with the AS04-adjuvanted cervical cancer vaccine: modeling of sustained antibody responses. Gynecol Oncol 2009, 115(3 Suppl):S1-6.

18. OECD Statextracts: http://stats.oecd.org/Index.aspx?DataSetCode=PPPGDP.

19. La Torre G, de Waure C, Chiaradia G, Mannocci A, Capri S, Ricciardi W: The Health Technology Assessment of bivalent HPV vaccine Cervarix in Italy. Vaccine 2010, 28:3379-3384.

20. Coupé VM, van Ginkel J, de Melker HE, Snijders PJ, Meijer CJ, Berkhof J: HPV16/18 vaccination to prevent cervical cancer in The Netherlands: model-based cost-effectiveness. Int J Cancer 2009, 124:970-978.

21. de Kok IM, van Ballegooijen M, Habbema JD: Cost-effectiveness analysis of human papillomavirus vaccination in the Netherlands. J Natl Cancer Inst 2009, 101:1083-1092.

22. Goldie SJ, Kohli M, Grima D, Weinstein MC, Wright TC, Bosch FX, Franco E: Projected clinical benefits and cost-effectiveness of a human papillomavirus 16/18 vaccine. J Natl Cancer Inst 2004, 96:604-615.

23. Torvinen S, Nieminen $\mathrm{P}$, Lehtinen M, Paavonen J, Demarteau N, Hahl J: Cost effectiveness of prophylactic HPV 16/18 vaccination in Finland: results from a modelling exercise. J Med Econ 2010, 13:284-294.

24. Sanders GD, Taira AV: Cost-effectiveness of a potential vaccine for human papillomavirus. Emerg Infect Dis 2003, 9:37-48.

25. Obradovic M, Mrhar A, Kos M: Cost-effectiveness analysis of HPV vaccination alongside cervical screening programme in Slovenia. Eur J Public Health 2010, 20:415-421.

26. Taira AV, Neukermans CP, Sanders GD: Evaluating human papillomavirus vaccination programs. Emerg Infect Dis 2004, 10:1915-1923.

27. Insinga RP, Dasbach EJ, Elbasha EH, Puig A, Reynales-Shigematsu LM: Costeffectiveness of quadrivalent human papillomavirus (HPV) vaccination in Mexico: a transmission dynamic model-based evaluation. Vaccine 2007, 26:128-139.

28. Bergeron C, Largeron N, McAllister R, Mathevet P, Remy V: Costeffectiveness analysis of the introduction of a quadrivalent human papillomavirus vaccine in France. Int J Technol Assess Health Care 2008, 24:10-19.

29. Brisson M, Van de Velde N, De Wals P, Boily MC: The potential cost-effectiveness of prophylactic human papillomavirus vaccines in Canada. Vaccine 2007, 25:5399-5408.

30. Szucs TD, Largeron N, Dedes K, Rafia R, Bénard S: Cost-effectiveness analysis of adding a quadrivalent HPV vaccine to the cervical screening programme in Switzerland. Curr Med Res Opin 2008, 24:1473-1483.

31. Kulasingam S, Connelly L, Conway E, Hocking JS, Myers E, Regan DG, Rode D, Ross J, Wain G: A cost-effectiveness analysis of adding a human papillomavirus vaccine to the Australian National Cervical screening Program. Sex Health 2007, 4:165-175.

32. Ginsberg GM, Fisher M, Ben-Shahar I, Bornstein J: Cost-utility analysis of vaccination against HPV in Israel. Vaccine 2007, 25:6677-6691.

33. Olsen J, Jepsen MR: Human papillomavirus transmission and cost-effectiveness of introducing quadrivalent HPV vaccination in Denmark. Int J Technol Assess Health Care 2010, 26:183-191.

34. Dasbach EJ, Largeron N, Elbasha EH: Assessment of the cost-effectiveness of a quadrivalent HPV vaccine in Norway using a dynamic transmission model. Expert Rev Pharmacoecon Outcomes Res 2008, 8:491-500.

35. Kulasingam SL, Benard S, Barnabas RV, Largeron N, Myers ER: Adding a quadrivalent human papillomavirus vaccine to the UK cervical screening programme: A cost-effectiveness analysis. Cost Eff Resour Alloc 2008, 6:4.

36. Dee A, Howell F: A cost-utility analysis of adding a bivalent or quadrivalent HPV vaccine to the Irish cervical screening programme. Eur J Public Health 2010, 20:213-9.

37. Newall AT, Beutels P, Wood JG, Edmunds WJ, Maclntyre CR: Cost-effectiveness analyses of human papillomavirus vaccination. Lancet Infect Dis 2007, 7:289-96.

38. Insinga RP, Dasbach EJ, Elbasha EH: Structural differences among cost-effectiveness models of human papillomavirus vaccines. Expert Rev Vaccines 2008, 7:895-913.
39. Kim JJ, Brisson M, Edmunds WJ, Goldie SJ: Modeling cervical cancer prevention in developed countries. Vaccine 2008, 26(Suppl 10):K76-86.

40. Van de Velde N, Brisson M, Boily MC: Understanding differences in predictions of HPV vaccine effectiveness: A comparative model-based analysis. Vaccine 2010, 28:5473-5484.

41. Postma MJ: Cost-effectiveness analysis of Human Papillomavirus (HPV) vaccination in the Netherlands: recent publication reinforces favorable cost-effectiveness despite misleading conclusion. Vaccine 2010, 28:873-874.

42. Drummond M, Barbieri M, Cook J, Glick HA, Lis J, Malik F, Reed SD, Rutten F, Sculpher M, Severens J: Transferability of economic evaluations across jurisdictions: ISPOR Good Research Practices Task Force report. Value Health 2009, 12:409-418.

43. Dasbach EJ, Nagy L, Brandtmüller A, Elbasha EH: The cost effectiveness of a quadrivalent human papillomavirus vaccine $(6 / 11 / 16 / 18)$ in Hungary. J Med Econ 2010, 13:110-118.

\section{doi:10.1186/1471-2458-12-924}

Cite this article as: Vokó et al: Cost-effectiveness of adding vaccination with the AS04-adjuvanted human papillomavirus $16 / 18$ vaccine to cervical cancer screening in Hungary. BMC Public Health 2012 12:924.

\section{Submit your next manuscript to BioMed Central and take full advantage of:}

- Convenient online submission

- Thorough peer review

- No space constraints or color figure charges

- Immediate publication on acceptance

- Inclusion in PubMed, CAS, Scopus and Google Scholar

- Research which is freely available for redistribution 